\title{
Analysis of speech fluency in Williams syndrome
}

\author{
Natalia Freitas Rossi ${ }^{\mathrm{a}, *}$, Adriana Sampaio ${ }^{\mathrm{b}}$, Óscar F. Gonçalves ${ }^{\mathrm{b}}$, Célia Maria Giacheti ${ }^{\mathrm{a}}$ \\ a Department of Speech-Language Pathology, Phylosophy and Sciences Faculty, University Estadual Paulista (UNESP), Marília Campus, Avenida Hygino Muzzi Filho, \\ 737. CEP: 17525-900, Marília, São Paulo, Brazil \\ ${ }^{\mathrm{b}}$ Neuropsychophysiology Lab, CIPsi, School of Psychology, University of Minho, Braga, Portugal
}

\section{A R T I C L E I N F O}

\section{Article history:}

Received 21 April 2011

Received in revised form 22 April 2011

Accepted 3 May 2011

Available online 31 May 2011

\section{Keywords:}

Fluency

Oral narrative

Language

Williams syndrome

\begin{abstract}
A B S T R A C T
Williams syndrome (WS) is a neurodevelopmental genetic disorder, often referred as being characterized by dissociation between verbal and non-verbal abilities, although the number of studies disputing this proposal is emerging. Indeed, although they have been traditionally reported as displaying increased speech fluency, this topic has not been fully addressed in research. In previous studies carried out with a small group of individuals with WS, we reported speech breakdowns during conversational and autobiographical narratives suggestive of language difficulties. In the current study, we characterized the speech fluency profile using an ecologically based measure - a narrative task (story generation) was collected from a group of individuals with WS $(n=30)$ and typically developing group $(n=39)$ matched in mental age. Oral narratives were elicited using a picture stimulus - the cookie theft picture from Boston Diagnosis Aphasia Test. All narratives were analyzed according to typology and frequency of fluency breakdowns (non-stuttered and stuttered disfluencies). Oral narratives in WS group differed from typically developing group, mainly due to a significant increase in the frequency of disfluencies, particularly in terms of hesitations, repetitions and pauses. This is the first evidence of disfluencies in WS using an ecologically based task (oral narrative task), suggesting that these speech disfluencies may represent a significant marker of language problems in WS.
\end{abstract}

(c) 2011 Elsevier Ltd. All rights reserved.

\section{Introduction}

Williams syndrome (WS) is a neurodevelopmental disorder, with a prevalence of 1 in 7500 (Strømme, Bjømstad, \& Ramstad, 2002), characterized by a deletion in chromosome 7q11.23 (Ewart et al., 1993) comprising a 1.5-1.8Mb and loss of approximately 22 genes in this region (Bayés, Magano, Rivera, Flores, \& Péres Jurado, 2003).

Individuals with WS are commonly characterized as displaying an intriguing neurocognitive functioning, described as the "Williams Syndrome Cognitive Profile", in which a dissociation between cognitive domains, namely between verbal and non-verbal abilities, is described (Atkinson et al., 2001; Grant, Valian, \& Karmiloff-Smith, 2002; Jarrold, Baddeley, \& Hewes, 1998; Jarrold, Baddeley, Hewes, \& Phillips, 2001; Mervis et al., 2000; Pagon, Bennett, LaVeck, Stewart, \& Johnson, 1987; Stiles, Sabbadini, Capirci, \& Volterra, 2000; Udwin \& Yule, 1990). Specifically, the evidence of a superior performance in verbal tasks in WS has been proposed as being the result of an effective contribution of the working memory phonological loop in promoting retention and manipulation of verbal items and thus enhancing syntactic abilities (Jarrold et al., 2001; Nichols et al., 2004; Vicari, Bellucci, \& Carlesimo, 2001; Vicari et al., 2004; Volterra, Caselli, Capirci, Tonucci, \& Vicari, 2003;

\footnotetext{
* Corresponding author. Tel.: +55 14 34021324; fax: +55 1434224797.

E-mail address: nataliafreitasrossi@yahoo.com.br (N.F. Rossi).
} 
Wang \& Bellugi, 1994). Additionally, an association between a proficient, well-articulated and grammatically correct speech fluency profile occurring in the context of impaired intellectual disabilities and an overfriendly personality, excessive use of social clichés and tendency to introduce personal experiences out of context, constituted the "Cocktail Party Speech, CPS" (Udwin \& Yule, 1990).

However, this notion of spared verbal abilities was challenged and subsequent studies demonstrated that linguistic functions in WS are as impaired as other cognitive domains (Brock, 2007; Karmiloff-Smith, Brown, Grice, \& Paterson, 2003; Sampaio, Sousa, Fernandez, Henriques, \& Goncalves, 2008). Indeed, the number of studies disputing the hypothesis of verbal-nonverbal dissociation in WS cognitive architecture is growing and, most importantly, contributing to mounting evidence for impaired language abilities in WS, including features traditionally referred as "specific" of WS phenotype, specifically, increased fluency and vocabulary. Indeed, while some studies arguing that individuals with WS perform very well on semantic and phonological fluency tasks (Rossen, Bihrlie, Klima, Bellugi, \& Jones, 1996), others have been proving inconsistent results, namely the evidence of similar and/or impaired performances in comparison with mental and chronological-age controls (Grant et al., 2002; Jarrold, Hartley, Phillips, \& Baddeley, 2000; Marini, Martelli, Gagliardi, Fabbro, \& Borgatti, 2010; Stojanovik \& van Ewijk, 2008; Vicari et al., 2004).

Semantic recall tasks are widely used in language and neuropsychological studies particularly because they provide important cues regarding word recovery (semantic memory) taking into account a specific semantic category (e.g., names of animals) or words that begin with the same sound or letter (e.g., say words that begin with F, A or S) (Binetti et al., 1996) within a time limit. The number of lexical items that an individual is able to recall is described as an index of verbal fluency. This measure seems to be more associated with language processing within lexical-semantic domain, and less within syntactic-semantic domain. Thus, performance in standardized tasks requiring semantic recall tends to be less ecologically oriented and provide a limited characterization of verbal fluency phenotype in WS. Therefore, narrative has a considerable value in eliciting speech samples, and thus fluency assessment should include connected speech samples that can be obtained using ecologically based measures occurring naturally in children's environments, given that narrative abilities serve as indices for assessing several developmental domains (e.g., pragmatics, emotion, cognitive inferences, etc.), and more importantly, can be considered predictors of language development and (Bajaj, 2007). Studies that privileged oral narrative contexts to assess language abilities in WS showed that their narratives are characterized by an excessive use of prosodic markers and audience engaging mechanisms that give the idea that they are truly "natural story tellers" (Bellugi, Lichtenberger, Jones, Lai, \& St. George, 2000; Gonçalves et al., 2004), despite impairments in narrative structure, mainly in semantic coherence, have also been described (Goncalves et al., 2010; Gonçalves et al., 2011; Marini et al., 2010; Reilly, Losh, Bellugi, \& Wulfeck, 2004). Disfluencies as hesitations and false starts have been interpreted as being part of their difficulties in lexical-semantic access (Karmiloff-Smith et al., 2003; Marini et al., 2010; Reilly et al., 2004), although no formal analysis of their speech fluency profile was formally presented.Preliminary data on speech fluency profile in 12 individuals with WS using a conversational (Rossi, Moretti-Ferreira, \& Giacheti, 2007) and autobiographical narrative tasks (Rossi, Souza, MorettiFerreira, \& Giacheti, 2009) evidenced an increased frequency of hesitations and word repetitions in the WS group when compared with typically developing individuals matched in mental-age, suggesting that these type of disfluencies could be related with their difficulties in lexical-semantic and syntactic access. Indeed, an emerging field of research has been consistently questioning the idea that language is an intact ability in WS (Karmiloff-Smith et al., 2003). However, even though fluency is associated with the cognitive and language profile of this syndrome, the pattern of speech fluency is indeed one of the most remarkable characteristic exhibited by individuals with WS, which has been inclusively used as a differential speech language phenotype marker regarding other genetic conditions such as Down and Fragile X syndromes.

Despite the fact that the "speech fluency" has been associated with one of the phenotypic characteristics of WS, this dimension has been relatively unexplored and studies providing a characterization of the speech fluency profile of WS (considering frequency and typology of disfluencies) were, to the best of our knowledge, not done yet. Thus, an analysis on frequency and typology of speech language in complex linguistic tasks (e.g., narrative) could reveal aspects not only related with discourse organization and planning, but also more related to language itself.Thus the objective of this study is to characterize the speech fluency profile (type and disfluencies frequency) using a narrative task (story generation) in a large group of individuals with WS in comparison with typically developing individuals matched in terms of mental age.

\section{Method}

\subsection{Participants}

The participants consist of 30 individuals with WS (15 males and 15 females), positive to Elastin gene deletion confirmed by FISH analysis with mean chronological age ranging between 6 and 27 years $(M=14.70, S D=4.60)$ and mental age 4.815.1 years $(M=8.20, \mathrm{SD}=3.10)$ that were compared with 39 individuals with typically language development (19 males and 20 females, mean chronological age 7.9, $\mathrm{SD}=3.3$ ), matched in mental age. Intellectual functioning was assessed using Wechsler Intelligence Scales - preschool, children and adult versions (Wechsler, 1989, 1991, 1997) - see Table 1.

The present study was approved by the Ethic Committee of the Faculdade de Medicina de Botucatu - UNESP Campus, the second OF. 256/2006-CEP-FMB-UNESP. Each participant (or their parents) gave written informed consent for their participation in the study via consent forms, after a complete description of the study. 
Table 1

Characterization of WS and typically developing groups.

\begin{tabular}{|c|c|c|c|c|c|c|c|c|c|c|c|c|}
\hline & \multicolumn{6}{|c|}{ WS $(N=30)$} & \multicolumn{6}{|c|}{$\mathrm{TD}(N=39)$} \\
\hline & \multirow[t]{2}{*}{$M$} & \multirow[t]{2}{*}{ SD } & \multirow[t]{2}{*}{ Range } & \multicolumn{3}{|c|}{ Percentile } & \multirow[t]{2}{*}{$M$} & \multirow[t]{2}{*}{ SD } & \multirow[t]{2}{*}{ Range } & \multicolumn{3}{|c|}{ Percentile } \\
\hline & & & & 25 th & 50 th & 75 th & & & & 25 th & 50 th & 75 th \\
\hline $\mathrm{CA}$ & 14.8 & 6.7 & $6.0-27.0$ & 11.0 & 15.0 & 17.0 & 8.1 & 3.3 & $3.2-15.3$ & 5.8 & 7.4 & 10.5 \\
\hline MA & 8.2 & 3.1 & $4.8-15.1$ & 6.2 & 7.0 & 9.3 & 7.9 & 3.3 & $2.9-15.1$ & 5.8 & 7.1 & 10.9 \\
\hline VIQ & 59.6 & 11.1 & $45.0-78.0$ & 47.7 & 61.5 & 67.5 & 98.2 & 3.1 & $92.0-106.0$ & 97.0 & 98.0 & 100.0 \\
\hline PIQ & 56.8 & 11.3 & $35.0-78.0$ & 47.0 & 58.0 & 66.0 & 98.3 & 3.2 & $91.0-105.0$ & 97.0 & 99.0 & 100.0 \\
\hline FSIQ & 56.2 & 10.9 & $35.0-78.0$ & 46.0 & 56.5 & 66.5 & 97.8 & 3.5 & $91.0-106.0$ & 95.0 & 97.0 & 100.0 \\
\hline
\end{tabular}

$\mathrm{CA}=$ chronological age; $\mathrm{MA}=$ mental age; $\mathrm{VIQ}=$ verbal $\mathrm{IQ} ; \mathrm{PIQ}=$ performance $\mathrm{IQ} ; \mathrm{FSIQ}=$ full scale IQ; $M=$ mean; $\mathrm{SD}=$ standard deviation .

\subsection{Procedure}

The oral narrative was elicited using a picture stimulus - the cookie theft picture from Boston Diagnosis Aphasia Test (Goodglass \& Kaplan, 1983). The narrative was collected in one session in a quiet room and individuals were given the following instruction "I would like you to tell me a history using this picture". The story was considered finished anytime a typical linguistic end marker was used (e.g., "That's all!”) or stopped for five or more minutes. After that marker or stop, individuals were still prompted with the questions: "Did you finished? Would you like to say anything else about the story?" During the narrative generation protocol, only minimal verbal encouragements were provided as an incentive to pursue with the narrative (e.g., uhm.uhm; "and then" and "what else"). All narratives were audio and videotaped. For the audiotape procedure we used a head microphone, unidirectional, positioned in $5 \mathrm{~cm}$ distance from the mouth and connected to a laptop.

Narrative samples were fully transcribed and coded according to Andrade (2004) for the following dimensions: speech disruption typology (typical or stutter disfluencies), frequency of disruption and the flow of verbal information (speech rate). Disfluencies were classified in: (1) typical disfluencies (hesitations, interjections, revisions, unfinished words, segment repetitions and sentence repetitions) which are more related with language processing and; (2) stutter disfluencies (two or more sound repetitions and/or syllable, and/or words; prolonging, block, pauses and intrusions), which are more related with speech processing (Andrade, 2004). From these parameters, it was possible to compute the percentage of speech discontinuity (presence of common and stutter disfluencies; percentage of stutter disfluencies; percentage of common disfluencies).

Speech rate or verbal information flow was analyzed according to the number of words and syllables/min (including the duration of the pauses). The total time of the speech sample, as well as the number of pauses and its duration was analyzed with PRAAT software, version 5.1. A pause was considered any interruption in verbal production with duration $\geq 2 \mathrm{~s}$ ( $\geq 0.03 \mathrm{~min}$ ), as suggested by Andrade (2004).

\subsection{Data analysis}

Descriptive analysis included mean (M), standard deviation (SD), minimum (M), maximum (Max) and quartile distribution 25th, 50th and 75th. Exploratory analyses were performed to testing normality and variance homogeneity. Thus, a Mann Whitney $U$ test was used to compare two independent samples and a Spearman test was used to assess correlation between variables. A $p$ value less than 0.05 was established for statistical significance. PASW Statistic, v.17.0.2 was used to perform all statistical analyses.

\section{Results}

Comparative analysis of the fluency profile obtained in the context of an oral narrative through an action picture description showed differences between WS and typically developing groups, mainly in typical disfluencies such as hesitations $\left(M_{\mathrm{WS}}=7.9, \mathrm{SD}=8.9 ; M_{\mathrm{TD}}=2.6, \mathrm{SD}=1.0 ; U=99, p<.001\right)$ word repetition $\left(M_{\mathrm{WS}}=6.5, \mathrm{SD}=24.1 ; M_{\mathrm{TD}}=0.8\right.$, $\mathrm{SD}=0.9 ; U=420.5, p=.04)$, segment repetition $\left(M_{\mathrm{WS}}=1.8, \mathrm{SD}=5.8 ; M_{\mathrm{TD}}=0.2, \mathrm{SD}=0.5 ; U=354.5, p<.001\right)$. An increasing in stutter disfluencies as prolongation $\left(M_{\mathrm{WS}}=0.9, \mathrm{SD}=2.9 ; M_{\mathrm{TD}}=0.0, \mathrm{SD}=0.0 ; U=507, p<.05\right)$ and blocking types $\left(M_{\mathrm{WS}}=1.0\right.$, $\mathrm{SD}=5.1 ; M_{\mathrm{TD}}=0.0, \mathrm{SD}=0.0 ; U=526.5, p=.05$ - see Table 2$)$ were evident in WS.

Comparing both groups according to the pause type ruptures, we found that the WS group showed significantly more pauses than TD group $\left(M_{\mathrm{WS}}=4.9, \mathrm{SD}=3.1 ; M_{\mathrm{TD}}=3.2, \mathrm{SD}=2.4 ; U=396, p<.05-\right.$ see Table 2$)$, as well as a significant increase in pause duration $\left(M_{\mathrm{WS}}=3.8, \mathrm{SD}=1.2 ; M_{\mathrm{TD}}=3.0, \mathrm{SD}=1.1 ; U=328.5, p<.01\right)$.

As shown in Fig. 1, the narratives of individuals WS had significant less number of words $(U=293, p<.001)$ and syllables/ $\min (U=306, p<.01)$ when compared with narratives exhibited by typically developing group.

When we correlated the types of frequent disfluencies with the proportion of frequent disfluencies, we observed that hesitation $\left(r_{\mathrm{sp}}=.45, p<.05\right)$, unfinished word $\left(r_{\mathrm{sp}}=.40, p<.05\right)$ and segment repetition $\left(r_{\mathrm{sp}}=.45, p<.05\right)$ were the 
Table 2

Typology and frequency of disfluencies evidenced by individuals with WS and TD in the narrative task.

\begin{tabular}{|c|c|c|c|c|c|c|c|c|c|c|c|c|c|c|c|}
\hline \multirow[t]{3}{*}{ Disfluencies } & \multicolumn{7}{|c|}{ WS $(n=30)$} & \multicolumn{7}{|c|}{$\mathrm{TD}(n=39)$} & \multirow[t]{3}{*}{$p$} \\
\hline & \multirow[t]{2}{*}{$M$} & \multirow[t]{2}{*}{ SD } & \multirow[t]{2}{*}{ Min } & \multirow[t]{2}{*}{ Max } & \multicolumn{3}{|c|}{ Percentile } & \multirow[t]{2}{*}{$M$} & \multirow[t]{2}{*}{ SD } & \multirow[t]{2}{*}{ Min } & \multirow[t]{2}{*}{ Max } & \multicolumn{3}{|c|}{ Percentile } & \\
\hline & & & & & 25 th & 50th & 75 th & & & & & 25 th & 50 th & 75 th & \\
\hline \multicolumn{16}{|l|}{ Typical } \\
\hline Hesitations & 7.9 & 8.9 & 2.0 & 50.0 & 4.0 & 5.5 & 7.3 & 2.6 & 1.0 & 0.0 & 5.0 & 2.0 & 3.0 & 3.0 & $.00^{* *}$ \\
\hline Interjections & 3.2 & 6.5 & 0.0 & 27.0 & 0.0 & 1.0 & 4.0 & 0.6 & 0.8 & 0.0 & 3.0 & 0.0 & 0.0 & 1.0 & .09 \\
\hline Revision & 1.5 & 2.1 & 0.0 & 10.0 & 0.0 & 1.0 & 2.3 & 1.1 & 1.0 & 0.0 & 3.0 & 0.0 & 1.0 & 2.0 & .69 \\
\hline Unfinished word & 1.0 & 1.6 & 0.0 & 5.0 & 0.0 & 0.0 & 1.3 & 0.5 & 0.9 & 0.0 & 3.0 & 0.0 & 0.0 & 1.0 & .32 \\
\hline Word repetition & 6.5 & 24.1 & 0.0 & 13.0 & 0.0 & 2.0 & 3.3 & 0.8 & 0.9 & 0.0 & 3.0 & 0.0 & 1.0 & 2.0 & $.04^{*}$ \\
\hline Segment repetition & 1.8 & 5.8 & 0.0 & 32.0 & 0.0 & 0.5 & 1.0 & 0.2 & 0.5 & 0.0 & 2.0 & 0.0 & 0.0 & 0.0 & $.00^{* *}$ \\
\hline Sentence repetition & 0.8 & 2.9 & 0.0 & 16.0 & 0.0 & 0.0 & 1.0 & 0.3 & 0.5 & 0.0 & 2.0 & 0.0 & 0.0 & 0.0 & .62 \\
\hline \multicolumn{16}{|l|}{ Stuttering } \\
\hline Syllable repetition & 1.4 & 6.2 & 0.0 & 34.0 & 0.0 & 0.0 & 0.0 & 0.2 & 0.5 & 0.0 & 2.0 & 0.0 & 0.0 & 0.0 & .53 \\
\hline Sound repetition & 0.0 & 0.0 & 0.0 & 0.0 & 0.0 & 0.0 & 0.0 & 0.0 & 0.0 & 0.0 & 0.0 & 0.0 & 0.0 & 0.0 & 1.00 \\
\hline Prolongation & 0.9 & 2.9 & 0.0 & 12.0 & 0.0 & 0.0 & 0.0 & 0.0 & 0.0 & 0.0 & 0.0 & 0.0 & 0.0 & 0.0 & $.02^{*}$ \\
\hline Blocking & 1.0 & 5.1 & 0.0 & 28.0 & 0.0 & 0.0 & 0.0 & 0.0 & 0.0 & 0.0 & 0.0 & 0.0 & 0.0 & 0.0 & $.05^{*}$ \\
\hline Segment insertion & 0.1 & 0.4 & 0.0 & 2.0 & 0.0 & 0.0 & 0.0 & 0.0 & 0.0 & 0.0 & 0.0 & 0.0 & 0.0 & 0.0 & .10 \\
\hline Pauses & 4.9 & 3.1 & 0.0 & 14.0 & 2.8 & 4.5 & 7.0 & 3.2 & 2.4 & 0.0 & 7.0 & 1.0 & 3.0 & 5.0 & $.02^{*}$ \\
\hline \multicolumn{16}{|l|}{ Rupture frequency } \\
\hline \%Discourse discontinuing & 20.0 & 10.0 & 10.0 & 60.0 & 10.0 & 10.0 & 20.0 & 10.0 & 0.0 & 0.0 & 10.0 & 0.0 & 10.0 & 10.0 & $.00^{* * *}$ \\
\hline \%Stutter disfluency & 10.0 & 0.0 & 0.0 & 10.0 & 0.0 & 0.0 & 10.0 & 0.0 & 0.0 & 0.0 & 10.0 & 0.0 & 0.0 & 0.0 & $.00^{* *}$ \\
\hline \%Frequent disfluency & 10.0 & 10.0 & 0.0 & 40.0 & 10.0 & 10.0 & 20.0 & 0.0 & 0.0 & 0.0 & 10.0 & 0.0 & 0.0 & 10.0 & $.00^{* *}$ \\
\hline
\end{tabular}

$p<.05$.

*** $p<.001$.

disfluencies that most contributed to the frequent disfluency proportion evident in the speech sample of individuals with WS. Regarding the stutter disfluencies, only the variable pause showed a significant positive correlation $\left(r_{\mathrm{sp}}=.57, p<.01\right)$. We also analyzed the relation between the number of disfluencies and speech rate measures. Thus, we found that pauses were correlated with the number of words $/ \mathrm{min}\left(r_{\mathrm{sp}}=-.70, p<.001\right)$ and syllables $/ \mathrm{min}\left(r_{\mathrm{sp}}=.74, p<.001\right)$ as well as duration of pauses (words $/ \mathrm{min}, r_{\mathrm{sp}}=-.70, p<.001$ and syllables $/ \mathrm{min}, r_{\mathrm{sp}}=-.74, p<.001$ ) and the percentage of stuttering (words/ $\min , r_{\mathrm{sp}}=-.56, p<.01 ;$ syllables $\left./ \mathrm{min}, r_{\mathrm{sp}}=.-58, p<.01\right)$.

\section{Discussion}

The objective of the current study was to analyze speech fluency patterns in individuals with WS using a narrative task and compare their performance to a mental age matched group. The fluency profile of individuals with WS was different from their comparison group regarding non-stutter and stuttering disfluencies, namely by exhibiting an increased frequency of non-stuttering disfluencies such as hesitation, repetitions, unfinished words and pauses. Even though non-stuttering or typical disfluencies are considered part of speech language development, they may be also suggestive of cognitive and linguistic problems, particularly when the oral spoken is perceived as non-fluent or hesitative (Merlo, 2006) and this type of rupture exceeds typical developmental parameters (Guo, Tomblin, \& Samelson, 2008).

False starts and hesitations have already been reported as characteristic of speech language in WS, mostly associated with their lexical-semantic and syntactic impairments (Brock, 2007; Clahsen \& Almazan, 1998; Reilly et al., 2004; Temple,

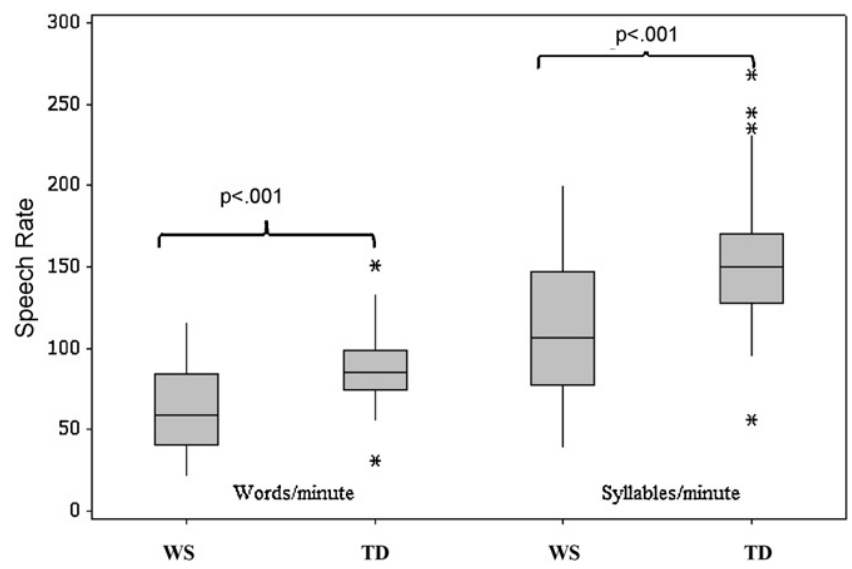

Fig. 1. Speech rate in WS and TD groups in the oral narrative of the action figure. 
Almazanb, \& Sherwooda, 2002), although these language subcomponents have been relatively unaddressed. Disfluencies are important sources of information regarding verbal information processing, namely they can denote difficulties occurring in different stages of verbal information production (e.g., conceptual planning; lexical retrieval; planning stage of speech articulation) (Bortfeld, Leon, Bloom, Schober, \& Brennan, 2001). These narrative speech problems displayed by individuals with WS individuals (i.e., poor coherence, formulation deficits and complex syntactical and semantic abnormalities) suggesting that the occurrence of non-stutter disfluencies is more likely to be associated with conceptual planning and lexical retrieval problems. Indeed, deficits in lexical access have already been reported as a common finding in WS (Brock, 2007; Clahsen \& Almazan, 1998; Temple et al., 2002) as well as abnormal semantic narrative coherence (Goncalves et al., 2010; Gonçalves et al., 2011; Marini et al., 2010; Reilly et al., 2004).

Regarding speech rate variables, our results showed that these were significantly influenced by the occurrence and time duration of pauses. Some researchers consider that pauses are related with cognitive process underlying language production (Goldman-Eisler, 1968), which appears to be likely in our group of individuals with WS. Thus, we showed that occurrence hesitation, repetition and pauses disfluencies were more evident in WS group, suggesting that these may be important indicators of difficulties in elaboration and organization of the oral narrative, and therefore, possibly associated with language processing rather than speech processing. Indeed, these types of disfluencies were also reported in narrative of individuals with specific language impairment (Guo et al., 2008).Comparing data from the current study with previous studies using different language tasks, it appears that individuals with WS evince more disfluencies (pauses and hesitations) in story generation when compared with conversational (Rossi et al., 2007) and autobiographical narrative tasks (Rossi et al., 2009). We hypothesize that this evidence could be associated with demanding cognitive and linguistic abilities required to produce a narrative scheme story and consequently with failures in accessing mental lexicon would be associated with inconsistencies within the narrative. Indeed, studies with individuals with typical developing language showed that there is an increased frequency of hesitation and pauses disfluencies in oral narrative tasks when compared with conversational tasks, mainly associated with the cognitive and linguistic requirements of narrative (Bishop, 1997) and the verbal production processes (Barr, 2003). Taking into account this evidence, the use of oral narrative tasks under a constrained topic (Stojanovik \& van Ewijk, 2008), together with a detailed speech fluency analysis is an interesting approach to investigate the effects of cognitive and linguistic requirements on the ability to process information at the perceptual, coding, attention, memory and planning levels (Bishop, 1997), and therefore having an impact in the verbal production process (Barr, 2003; O'Connell, Kowal, \& Hormann, 1969; Shriberg, 2001).Finally, the present data should be analyzed taking into account that the task used in this study was characterized by a visual description of a single picture with no sequential organized events that could impact the story generation process and thus contribute to language disfluencies. However, the occurrence of disfluencies (repetition and hesitation) in this story generation with a single picture task description together with the same evidence using autobiographical narrative tasks, suggest that this finding could not be attributed exclusively to the nature of stimulus itself and future studies using sequential pictures, as story books, may help to elucidate this methodological issue.

In conclusion, the present study provides for the first time evidence of disfluencies as hesitation, repetition and pauses in WS speech. The association of narrative assessment and fluency breakdowns could provide an important tool for understanding linguistic and cognitive deficits underlying WS phenotype.

\section{Acknowledgments}

This research was funded by a grant from: Conselho Nacional de Desenvolvimento Científico e Tecnológico (CNPq, Process GM/GD 141307/2006-4, MCT/CNPq 14/2009-474092/2009-7), Brazil, Coordenação de Aperfeiçoamento de Pessoal de Nível Superior (CAPES) - Programa de Doutorado no País com Estágio no Exterior (PDEE, Process 1551/08-6), Brazil and Fundação para a Ciência e Tecnologia (FCT, Process PTDC/PSI-PCL/115316/2009), Portugal.

We acknowledge Dr. Danilo Moretti-Ferreira by the clinical genetic assessment, a Deise Helena de Souza for the cytogenetic and molecular analysis, Cristiana Ferrari that contributed with the discussing and the Brazilian Williams Syndrome Association (ABSW).

\section{References}

Andrade, C. R. F. (2004). Fluência. In C. R. F. Andrade, D. M. Befi-Lopes, F. D. M. Fernandes, \& H. Wertzner (Eds.), ABFW: Teste de linguagem infantil nas áreas de fonologia, vocabulário, fluência e pragmática. Carapicuíba: Pró-Fono.

Atkinson, J., Anker, S., Braddick, O., Nokes, L., Mason, A., \& Braddick, F. (2001). Visual and visuospatial development in young children with Williams syndrome. Developmental Medicine E Child Neurology, 43(5), 330-337.

Bajaj, A. (2007). Analysis of oral narratives of children who stutter and their fluent peers: Kindergarten through second grade. Clinical Linguistics \& Phonetics, 21(3), 227-245.

Barr, D. J. (2003). Paralinguistic correlates of conceptual structure. Psychonomic Bulletin E Review, 10(2), 462-467.

Bayés, M., Magano, L. F., Rivera, N., Flores, R., \& Pérez Jurado, L. A. (2003). Mutational Mechanisms of Williams-Beuren Syndrome Deletions. American journal of human genetics, 73(1), 131-151.

Bellugi, U., Lichtenberger, L., Jones, W., Lai, Z., \& St. George, M. (2000). The neurocognitive profile of Williams syndrome: A complex pattern of strengths and weaknesses. Journal of Cognitive Neuroscience, 12(Suppl. 1), 7-29.

Binetti, G., Magni, E., Padovani, A., Cappa, S. F., Bianchetti, A., \& Trabucchi, M. (1996). Executive dysfunction in early Alzheimer's disease. Journal of Neurology, Neurosurgery \& Psychiatry, 60(1), 91-93.

Bishop, D. V. M. (1997). Uncommom understanding: Development and disorders of language comphrehension in children. Hove, UK: Psychology Press.

Bortfeld, H., Leon, S. D., Bloom, J. E., Schober, M. F., \& Brennan, S. E. (2001). Disfluency rates in conversation: Effects of age, relationship, topic, role, and gender. Language and Speech, 44(Pt. 2), 123-147. 
Brock, J. (2007). Language abilities in Williams syndrome: A critical review. Developmental and Psychopathology, 19(1), 97-127.

Clahsen, H., \& Almazan, M. (1998). Syntax and morphology in Williams syndrome. Cognition, 68(3), $167-198$.

Ewart, A., Morris, C., Atkinson, D., Jin, W., Sternes, K., Spallone, P., et al. (1993). Hemizygosity at the elastin locus in a developmental disorder, Williams syndrome. Nature Genetics, 5(1), 11-16.

Goldman-Eisler, F. (1968). Psycholinguistics: Experiments in spontaneous speech. New York: Academic Press.

Gonçalves, O. F., Pérez, A., Henriques, M., Prieto, M., Lima, M., Siebert, M., et al. (2004). Funcionamento Cognitivo e Produção Narrativa no Síndrome de Williams: Congruência ou Dissociação Neurocognitiva? International Journal of Clinical and Health Psychology, 4, $623-638$.

Gonçalves, Ó. , Pinheiro, A., Sampaio, A., Sousa, N., Férnandez, M., \& Henriques, M. (2011). Autobiographical Narratives in Williams Syndrome: Structural, Process and Content Dimensions. Journal of Developmental and Physical Disabilities, 1-14.

Goncalves, O. F., Pinheiro, A. P., Sampaio, A., Sousa, N., Fernandez, M., \& Henriques, (2010). The narrative profile in Williams syndrome: There is more to storytelling than just telling a story. The British Journal of Developmental Disabilities, 56(2), 89-109.

Goodglass, H., \& Kaplan, E. F. (1983). The assessment of aphasia and related disorders. Philadelphia, PA: Lea \& Febiger.

Grant, J., Valian, V., \& Karmiloff-Smith, A. (2002). A study of relative clauses in Williams syndrome. Journal of Child Language, $29(2), 403-416$.

Guo, L., Tomblin, J. B., \& Samelson, V. (2008). Speech disruptions in the narratives of english-speaking children with specific language. Journal of Speech, Language and Hearing Research, 51, 722-738.

Jarrold, C., Baddeley, A., \& Hewes, A. (1998). Verbal and nonverbal abilities in the Williams syndrome phenotype: Evidence for diverging developmental trajectories. The Journal of Child Psychology and Psychiatry, 39(4), 511-523.

Jarrold, C., Baddeley, A., Hewes, A., \& Phillips, C. (2001). A longitudinal assessment of diverging verbal and non-verbal abilities in the Williams syndrome phenotype. Cortex, 37(3), 423-431.

Jarrold, C., Hartley, S., Phillips, C., \& Baddeley, A. (2000). Word fluency in Williams syndrome: Evidence for unusual semantic organisation? Cognitive Neuropsychiatry, 5(4), 293-319.

Karmiloff-Smith, A., Brown, J., Grice, S., \& Paterson, S. (2003). Dethroning the myth: Cognitive dissociations and innate modularity in Williams syndrome. Developmental Neuropsychology, 23(1), 227-242.

Marini, A., Martelli, S., Gagliardi, C., Fabbro, F., \& Borgatti, R. (2010). Narrative language in Williams Syndrome and its neuropsychological correlates. Journal of Neurolinguistics, 23(2), 97-111.

Merlo, S. (2006). Hesitações na Fala Semi-Espontânea: Análise por Séries Temporais. Campinas: UNICAMP.

Mervis, C. B., Robinson, B. F., Bertrand, J., Morris, C. A., Klein-Tasman, B. P., \& Armstrong, S. C. (2000). The Williams syndrome cognitive profile. Brain and Cognition, 44(3), 604-628.

Nichols, S., Jones, W., Roman, M. J., Wulfeck, B., Delis, D. C., Reilly, J., et al. (2004). Mechanisms of verbal memory impairment in four neurodevelopmental disorders. Brain and Language, 88(2), 180-189.

O'Connell, D. C., Kowal, S., \& Hormann, H. (1969). Semantic determinants of pauses. Psychologische Forschung, $33,50-67$.

Pagon, R. A., Bennett, F. C., LaVeck, B., Stewart, K. B., \& Johnson, J. (1987). Williams syndrome: Features in late childhood and adolescence. Pediatrics, 80(1), 85-91.

Reilly, J., Losh, M., Bellugi, U., \& Wulfeck, B. (2004). “Frog, where are you?” Narratives in children with specific language impairment, early focal brain injury, and Williams syndrome. Brain and Language, 88(2), 229-247.

Rossen, M., Bihrlie, A., Klima, E. S., Bellugi, U., \& Jones, W. (1996). Interaction between language and cognition: Evidence from Williams syndrome. In J. H. Beitchman, N. Cohen, \& M. Konstantareas (Eds.), Language, learning and behaviour. New York: Cambridge University Press.

Rossi, N., Moretti-Ferreira, D., \& Giacheti, C. (2007). Perfil comunicativo de indivíduos com a síndrome de Williams-Beuren. Revista da Sociedade Brasileira de Fonoaudiologia, 12(1), 1-9.

Rossi, N., Souza, D., Moretti-Ferreira, D., \& Giacheti, C. (2009). Speech fluency profile in Williams-Beuren syndrome: A preliminary study. Pro Fono, 21(2), 107-111.

Sampaio, A., Sousa, N., Fernandez, M., Henriques, M., \& Goncalves, O. F. (2008). Memory abilities in Williams syndrome: Dissociation or developmental delay hypothesis? Brain and Cognition, 66(3), 290-297.

Shriberg, E. (2001). To 'errrr' is human: Ecology and acoustics of speech disfluencies. Journal of the International Phonetic Association, 31, 153-169.

Stiles, J., Sabbadini, L., Capirci, O., \& Volterra, V. (2000). Drawing abilities in Williams syndrome: A case study. Developmental Neuropsychology, 18(2), 213-235.

Stojanovik, V., \& van Ewijk, L. (2008). Do children with Williams syndrome have unusual vocabularies? Journal of Neurolinguistics, 21(1), 18-34.

Strømme, P., Bjømstad, P., \& Ramstad, K. (2002). Prevalence estimation of Williams syndrome. Journal of Child Neurology, $17(4), 269$.

Temple, C., Almazanb, M., \& Sherwooda, S. (2002). Lexical skills in Williams syndrome: A cognitive neuropsychological analysis. Journal of Neurolinguistics, 15(6), $463-495$.

Udwin, O., \& Yule, W. (1990). Expressive language of children with Williams syndrome. American Journal of Medical Genetics Supplement, 6, 108-114.

Vicari, S., Bates, E., Caselli, M. C., Pasqualetti, P., Gagliardi, C., Tonucci, F., et al. (2004). Neuropsychological profile of Italians with Williams syndrome: An example of a dissociation between language and cognition? Journal of the International Neuropsychological Society, 10(6), 862-876.

Vicari, S., Bellucci, S., \& Carlesimo, G. A. (2001). Procedural learning deficit in children with Williams syndrome. Neuropsychologia, 39(7), 665-677.

Volterra, V., Caselli, M. C., Capirci, O., Tonucci, F., \& Vicari, S. (2003). Early linguistic abilities of Italian children with Williams syndrome. Developmental Neuropsychology, 23(1-2), 33-58.

Wang, P., \& Bellugi, U. (1994). Evidence from two genetic syndromes for a dissociation between verbal and visual-spatial short-term memory. Journal of Clinical and Experimental Neuropsychology, 16(2), 317-322.

Wechsler, D. (1989). Wechsler preschool and primary scale of intelligence - Revised. San Antonio, TX: The Psychological Corporation.

Wechsler, D. (1991). Wechsler intelligence scale for children. Manual (3rd ed.). San Antonio: Psychological Corporation.

Wechsler, D. (1997). Wechsler adult intelligence scale. Manual (3rd ed.). San Antonio: Psychological Corporation. 